\title{
El FUndAMENTO DE UNA NACIÓN EN EL SURESTE NOVOHISPANO: A propósito de Votán, SACERdote Fundador de Palenque, (1773-1994)
}

\author{
Miguel Ángel Díaz Perera
}

Resumen: Partiendo de los desacuerdos en la discusión sobre el origen del hombre americano entre los siglos XVI y XVIII, el autor muestra cómo nociones involucradas se insertaron en el nacionalismo criollo de finales del siglo XVIII, que alimentado por la obtención de objetos prehispánicos a partir de expediciones anticuarias, sustentó argumentos históricos pre-independentistas en el sureste de la Nueva España. En este contexto, tomó relevancia Votán, un supuesto sacerdote fundador que, a pesar de su olvido a raíz de la consolidación del centralismo mexicano a partir de 1994, volvió a reaparecer para poner en entredicho la acción epicéntrica del Estado mexicano. Con esto se demuestra la existencia de una correlación entre voluntades eruditas y políticas que permiten entender al conocimiento histórico no como un ejercicio aséptico, puro y cristalino, sino como el foco de ardientes disputas, desde intereses contrapuestos y con impacto en los aconteceres del México moderno.

Palabras clave: Historia, política, Palenque, Votán, nacionalismo criollo, origen del hombre, migración fundacional.

Enviado a dictamen: 02 de mayo de 2012 Aprobación: 12 de junio de 2012

Revisiones: 1

Dr. Miguel Ángel Díaz Perera, Licenciado en historia por la Universidad Juárez Autónoma de Tabasco (UJAT), maestro y doctor en historia por el Centro de Estudios Históricos de El Colegio de Michoacán (El COLMICH), estancia posdoctoral en el Departamento de Investigaciones Educativas: Sección de Metodología y Teoría de la Ciencia del Centro de Investigación y de Estudios Avanzados del Instituto Politécnico Nacional (CINVESTAV). Actualmente, investigador del área académica Sociedad, Cultura y Salud, departamento de Salud, Equidad y Desarrollo Comunitario, línea de Investigación Culturas y Educación. Temas de interés: 1) Historia ambiental contemporánea de Tabasco, y 2) Historia del conocimiento, en particular, la formación disciplinar de las ciencias sociales. Correo electrónico: mdiaz@ecosur.mx.
Abstract: Based on the disagreements in the discussion on the origin of American man between the sixteenth and eighteenth centuries, the author shows how notions involved were inserted into the creole nationalism of the late eighteenth century, which nourished for obtaining pre-Hispanic objects from antiquarian expeditions, sustained pre-independence historical arguments in the southeast of New Spain. In this context, relevance took Votan, founding priest alleged that despite his forgetfulness as a result of the consolidation of Mexican centralism, from 1994, reappeared to challenge the Mexican state epicentral action. This demonstrates the existence of a correlation between scholarly and political wills that allow us to understand the historical knowledge not as an exercise aseptic, pure and clear, but as the focus of heated disputes, interests contradicted with impact on the happenings of modern Mexico.

Keywords: History, politics, Palenque, Votán, creole nationalism, human origins, migration founding.

\section{I}

\section{Planteamiento}

$\square$ n la segunda mitad del siglo XVIII surgió en la Nueva España una progresiva inquietud por explorar las ruinas prehispánicas. El coleccionismo, la visita de los sitios y el tráfico de objetos antiguos se convirtió en un recurso que, conforme transcurrieron los años, se propagó hasta alcanzar los albores del México independiente y volverse una 
plaga durante los siglos XIX y XX (Florescano, 1993; Morales, 1994; Alcina, 1995; Díaz, 2008). Sin embargo, ésta práctica encontró desde entonces nociones cargadas de conveniencias políticas que involucraron parte de una competencia entre grupos de poder novohispanos. Estos grupos pretendían asumir una noción de pasado en el contexto de la reivindicación del nacionalismo criollo que vio en la historia nativa el modelo de un futuro por tutelar y, con ello, la prefiguración de ambiciones independentistas o, posteriormente, separatistas. Esta búsqueda de fundamentos históricos apareció en varias regiones de la Nueva España y, para propósitos de este trabajo, importa analizar a uno que promovió como sede inaugural prehispánica el sur chiapaneco en una clara competencia con aquellos que sugerían el centro de México. Un punto donde se entrecruzaron voluntades eruditas y políticas que permiten entender al conocimiento histórico no como un ejercicio aséptico, puro y cristalino, sino como el foco de ardientes disputas, desde intereses contrapuestos y con impacto en los aconteceres de lo que sería el México naciente del siglo XIX.

Sin embargo, es imposible discernir la lógica de esta discusión sin escarbar en los siglos precedentes. Surgida en tiempos del descubrimiento, había persistidouna vieja competencia entre el sur y el norte (con sede final en el centro) de la Nueva España como escenarios del origen de los nativos producto de la incertidumbre por saber su procedencia en un territorio aparentemente separado de Europa. Esto tenía perturbadoras trascendencias teológicas. Si existía una pareja original (Adán y Eva) - se preguntaron cronistas como Sahagún, Acosta, Mendieta, Anglería y otros-, ientonces los europeos y los americanos descendían de la misma estirpe? y, si era así, ¿cómo llegaron estos hombres a América, en qué tiempo, bajo qué circunstancias, con qué tradiciones y cultura? (Matos, 1987). Esta irresolución permitió que surgieran teorías sobre un poblamiento pretérito, un cruce desconocido de Santo Tomás, un hijo perdido de Noé, una de las tribus perdidas de Israel, incluso el cruce de un segundo Adán. Así los nativos — se asumió — eran viejos europeos que habían construido aquellas ciudades magníficas después de una migración. Por lo general, los promotores del centro-norte referían la existencia de un estrecho terrestre entre ambos continentes y los segundos la presencia de una civilización de sabios navegantes como el rey Salomón, fenicios o vikingos. En efecto, estas teorías pretendían salvar la contradicción de suponer que los americanos pudieran tener un origen distinto y pervertir el mito de Adán y Eva como núcleo de la creación universal.

No obstante, para los siglos XVIII y XIX, este enigma se transformó en un problema que necesitó datación y demostración ante la nueva necesidad de probar y datar que exigía el conocimiento moderno. La historia antes concebida como un enorme rompecabezas trazado por un plan divino, donde el origen del hombre literalmente se explicaba por el Génesis, fue sustituida por la búsqueda del cambio continuo y se apeló a una verificación constituida por objetos y testimonios. Así fue como se volvió trascendental recurrir a los objetos y antigüedades con tal de definir una cronología fiable y desacralizada de los acontecimientos (Díaz Perera, 2008; Cañizares, 2007; Lippincott, et. al, 1999; Toulmin y Goodfield, 1990; Jay Gould, 1987). La vieja polémica del origen de las Indias supervivió pero se recompuso invocando nuevas coherencias aunque también inéditas trascendencias políticas. En este escenario, pensar el origen en el siglo XVIII implicó alentar la búsqueda de cimientos simbólicos para el llamado nacionalismo criollo. Lo que antes eran sólo piedras de ruinas perdidas, a los ojos del descontento novohispano, se volvieron evidencia de un pasado grandioso que se asumió como la esperanza de un futuro libre de la tutela peninsular. Pero la falta de consenso en las antiguas teorías sobre la procedencia nativa fundamentó desacuerdos entre los grupos de poder regional. Algunos eruditos, gracias al análisis de códices, creyeron encontrar las raíces en las ruinas del centro de la Nueva España, no obstante, al igual que un 
grupo de inquietos eruditos chiapaneco-guatemaltecos, buscaron en la riqueza monumental de sus alrededores otro origen y con ello el fundamento de posibilidad de un territorio propio. De esta manera, las posturas que apelaban al centro-norte o al sur conllevaron un debate sobre la trascendencia de los fundamentos epicéntricos y fundacionales de la posterior nación mexicana dentro de una competencia entre el núcleo central novohispano y el sur, más vinculado al reino de Guatemala, donde al cabo de los años triunfaría la primera sobre la segunda y aplastaría aquellas raíces fallidas de esta región lejana y oscurecida detrás de kilómetros de selva y calor sofocante.

\section{II}

¿El norte o el sur?, ¿ por mar o tierra?, revisión de la discusión

El principal promotor de Tollan y la migración terrestre por el norte en el siglo XVIII fue el jesuita expulso Francisco Xavier Clavijero (1731-1787). En su Historia antigua de México publicada en Italia en 1780 sostuvo un cruce "el cual sin duda es el mismo que descubrieron los viajeros enel sigloXVIy llamaronestrecho de Anam", por consiguiente:

Los progenitores de las naciones que poblaron el país de Anáhuac (de quienes ahora simplemente hablamos), pasaron de los países septentrionales de Europa a los septentrionales de América, o más bien de los países más orientales de Asia a los más occidentales de América. Esta conclusión se funda en la constante y general tradición de aquellas naciones, que unánimemente decían haber sido sus progenitores gente venida a Anáhuac de los países situados al Norte y al Nordeste (Clavijero, 1964: 435).

No obstante, la teoría del sur tomó realce con la publicación londinense en 1822 de un informe del capitán español Antonio del Río que había explorado Palenque e incluía unas imágenes litografiadas por
Frédéric Waldeck titulado Description of the Ruins of an Ancient City, Discovered near Palenque... from the Original Manuscript Report of Captain Don Antonio del Rio: Followed by Teatro Critico Americano by Doctor Paul Felix Cabrera (Del Río, 1822). Ahí, en el estudio de Cabrera, se sostenía la llegada de un sacerdote llamado Votán (Navarrete, 1991: 9-55), fundador de Natchán (Palenque) y mentor en la elaboración de edificios, esculturas y técnicas que evidenciaban supuestos contagios entre el Viejo y Nuevo Mundo. Posición distinta que ganaría adeptos de acuerdo a que ambas teorías, desde hacía varios siglos, habían sido difundidas en los círculos intelectuales.

Un ejemplo claro de estas añejas permanencias fue Edward King, vizconde de Kingsborough, contrabandista y autor de una de las compilaciones de códices más completa de mediados del siglo XIX, Antiquities of Mexico, que sostenía que los americanos pertenecían a las diez tribus perdidas de Israel, es decir, provenían del Viejo Mundo a través de una migración por el norte (Huddleston, 1967: 33-34). No obstante, el principal protector de esta explicación había sido Juan Suárez de Peralta (1537-i?), español, vecino de México, a través de su Tratado del descubrimiento de las Indias y su conquista y de los ritos y sacrificios y costumbres de los Indios (Suárez, 1949. En especial, véase el capítulo l "Que trata sobre el origen y principio de las indias e indios, y de las opiniones que en ello y sobre ello hay"). Fray Diego Durán (1537-1588) también defendía este origen con respecto a los pueblos del centro de México (Durán, 1995). En 1650, Manoel Dias Soeiro mejor conocido como Manaseh Ben Israel (1604-1657), escritor y diplomático portugués, seguía aseverando esta teoría en su Esperanza de Israel, (Ben Israel, 1987: 103 y 104) y fuera de España fue el teólogo Joannes Fredericus Lumnius (1533-1602) con su texto De Extremo Dei Iudicio et Indorum Vocatione, publicado en Venecia en 1567 (Bernal, 1979: 25).

Sin embargo, la tesis de una migración marítima en relación al sur también hundía sus raíces en el siglo XVI. Inspirándose en relatos bíblicos, el cronista Pedro Mártir de Anglería (1456-1526), escribió aunque 
sin referirse explícitamente al sur pero sí al oriente: "habiendo, pues, puesto [Colón] rumbo hacia oriente, cuenta que descubrió la isla de Ofir; pero bien examinados los diseños de los cosmógrafos, aquellas son las Antillas y otras islas adyacentes: dio a ésta el nombre de Española." (Anglería, 1964: 105), en Década 1, libro 1, Anglería se refería a una isla citada en el Libro de los Reyes que también retomó Benito Arias Montano (1527-1589) en su Biblia Sacra (Huddleston, 1967: 41-42). La versión de judíos o hebreos en América fue retomada igualmente por el cronista Miguel Cabello de Valboa (1530?-1606) en su Miscelánea Antártica impreso en 1586, el alemán Gilbert Genebrand en su Chronografía in duos libros distincta de 1567, el cosmógrafo y franciscano francés André Thévet (1502-1590) y el inglés Thomas Thorowgood (Ibid: 24; Cogley, 304-330). En síntesis, Anglería y compañía, eran los principales propagandistas de una migración marítima por el sur en contraposición a una terrestre por el norte como insinuaron Durán y Lumnius con las diez tribus perdidas de Israel. Al mismo tiempo que la noción de un desembarco marítimo tomó adeptos, también creció la sospecha sobre un punto desconocido donde los continentes se interconectaban como habían propuesto en 1589 el jesuita José de Acosta (1540-1600) en Historia natural y moral de las Indias y fray Juan de Torquemada (1557?-1624) en Monarquía Indiana. Éste último no descartaba un desembarque por alguna civilización de navegantes, al igual que fray Bernardino de Sahagún (1499-1590) en Historia General de las cosas de la Nueva España (Matos, 1987: 33-49, 51-84 y 29-31 $)^{1}$ considerando una posible llegada de fenicios o cartagineses, situación que refrendó como probable el autor anónimo de Isagoge, Historia apologética de las Indias occidentales y a la cual se contrapuso (en el caso de Yucatán) el franciscano Diego López de Cogolludo (i?-1665) en 1659 con su Historia de Yucatán (Huddleston, 1967: 80-81; Bernal, 1979: 25). Cogolludo decía:

Quines fuesen se ignora, ni los indios tienen tradició de ello. Algunos han dicho, que son obras de
Cartaginenses, ó Phenicios; pero esto comunmente se refuta con las razones generales de no constar por Historias algunas aver pallado tales Naciones á estos Reynos. El Doctor Aguilar dize en su informe, que los hicieron Indios Mexicanos; pero no hallo que otro alguno diga tal cosa, y asi parece solamente fer conjetura suya (Cogolludo, 1957: 177.)

Con diversos matices, José de Acosta, el autor anónimo de Isagoge y Diego López de Cogolludo, se inclinaron por tratar de conciliar ambos extremos de la discusión. Cogolludo, por ejemplo, tuvo la idea de dos migraciones, una "de laparte Occidental, y otros de la Oriental", la segunda emprendida por un sacerdote llamado Zamná que había puesto nombre a todas las ciudades y puertos de mar en Yucatán, y la primera, fraguada por descendientes de los Chichimecas y Alcahuas del centro de México. Pero si aquí hubo espíritu concertador, también hubo posiciones extremas. En este punto estuvo la controvertida suposición de dos o más Adanes referida por Paracelso (1493-1541) en 1520 y que tomó fuerza en dos textos anónimos de 1655 del protestante francés Isaac de la Pereyre (1594-1676) (Huddleston, 1967: 138139.), que de inmediato fueron refutados por el célebre filósofo fray Benito Jerónimo Feijóo y Montenegro (1676-1764) (Feijóo y Montenegro, 1945). La tesis de un segundo Adán, peligrosa por su carga pluricreacionista y contraria al mito bíblico de una pareja original, mantuvo pocos pero significativos adeptos. De hecho, sirvió para voltear la discusión. Según Ignacio Bernal, el texto anónimo de Isagoge, Historia apologética de las Indias occidentales o la opinión del jurista Antonio León de Pinelo (1590-1660) sustentaban que Adán se había creado en América y después había cruzado a Europa y no a la inversa, esto con cierto arraigo en la creencia del almirante Cristóbal Colón cuando creyó estar en el Paraíso Terrenal. Con todo, la incertidumbre se mantuvo. Durante estos tres siglos se siguió asumiendo que sólo a través de la enseñanza de un hombre blanco, barbado, proveniente del Viejo Mundo como 
Quetzalcóatl o Votán se podía explicar la existencia de Palenque, Uxmal, Xochicalco o Teotihuacán y, en su efecto presente, sólo la nación mexicana era sostenible por la dirección de los criollos concebidos como entidad tutelar. De ahí la trascendencia del papel de una "ciudad original" hasta que justamente John Lloyd Stephens, "padre de la arqueología maya" en la segunda mitad del siglo XIX, enunció la independencia civilizatoria de los sitios prehispánicos para indirectamente hacer prosperar las cargas de transgresión que durante siglos habían insertado los pluricreacionistas herederos de La Pereyre. Pero para llegar a esta situación, hubieron de pasar todavía varios encuentros y desencuentros hasta llegar al siglo XIX y al siglo nuestro donde los intereses nacionalistas tomaron otros porvenires.

\section{III}

\section{De la justificación del colonialismo español al nacionalismo criollo}

Las posturas eruditas con mayor carga política proliferaron en el siglo XVIII. En el contexto del descontento novohispano que empezó a contagiar las elites criollas, apareció en escena Guillermo Dupaix (1750-1817), explorador al servicio de la Corona española de Xochicalco, Teotihuacán, Mitla, Monte Albán y Palenque entre 1805 y 1807. Este austriaco creyó en la existencia de un mítico continente, la Atlántida. Esta versión había sido esbozaba por Francisco López de Gómara (1511?-1566) en Historia general de las indias y vida de Hernán Cortés (López de Gómara, 1979; Huddleston, 1967: 25-26)² y sirvió precisamente para justificar la ocupación española. Gómara creía que al ser éstos los verdaderos descubridores de América, al momento de ser conquistados por Roma podían heredar su poder al papado y el Papa, a través de la famosa bula de Alejandro VI, al otorgar el poder "de todas las islas y tierra firme que descubriesen al occidente, con tal que, conquistándolas, enviasen allá predicadores a convertir los indios que idolatraban" (López de Gómara, 1979: 35; Bernal, 1979: 27.), se posibilitaba la cesión del derecho de tutela sobre el Nuevo Mundo. Esta necesidad de justificar la ocupación de América llevó a otros cronistas hacia versiones con iguales connotaciones políticas. Gonzalo Fernández de Oviedo (1478-1557) sería el representante más conocido de la leyenda del decimosegundo rey de España, Hespero, que en 1658 a.C. había conquistado unas islas oceánicas en el extremo oeste del océano Atlántico, conocidas posteriormente como las Hespérides (Fernández de Oviedo, 1959). Asimismo, la tesis de un cruce de Santo Tomás o San Bartolomé en tiempos de los apóstoles tuvo la misma indicación pero, en este caso, para animar la urgencia de la conversión religiosa (Pease, 1999). ${ }^{3}$ En la Nueva España, en algún momento, esta leyenda se mezcló con el mito de Quetzalcóatl y la Virgen de Guadalupe (Bernal, 1979: 28-29; Aguilar Camín, 1994: 8). Según denuncias, Fray Servando Teresa de Mier en un sermón predicado el 12 de diciembre de 1794, sostuvo:

que esta Portentosa imagen no fue pintada en la Capa ó Tilma del Indio Juan Diego, como sostiene la constante y recivida tradicion que de ella tenemos, sino que fué estampada en la Capa de Santo Thomas Apostol desde los principios del primer siglo de la Iglesia viviendo avn en carne mortal la Santisima Virgen, sobre lo que vertió en el mismo sermon otras muchas proposiciones escandalosas, milagros supuestos, y especies ridiculas y vanas ("Causa", 1985: 5, el expediente ocupa desde la página 5 hasta la 132).

Con ello, las versiones sobre el origen que justificaban la dominación española se empezaron a convertir paulatina y paradójicamente en fuente del nacionalismo criollo. Así, Carlos de Sigüenza y Góngora (1645-1700), jesuita expulso, historiador, matemático y cosmógrafo, le siguió el rastro a este mito para certificar el origen del hombre americano, aunque era partidario de la existencia de la Atlántida (Bernal, 1979: 28). El anticuario mexicano Mariano Veytia (1718-1779) en su Historia antigua de México recurrió a varios ejemplos de cruces 
cristianas en América anteriores a la llegada de los españoles "que prueban con más eficacia que Quetzalcohuatl fue alguno de los santos apóstoles o discípulos del Señor, que predicó el Evangelio e estas partes" (Veytia, t. I, 1979: 153). Por lo mismo, la imagen representada en el Templo de la Cruz de Palenque tuvo un valor agregado para los cronistas y anticuarios que creían se remontaba a una antigua evangelización americana. De hecho, Francisco Xavier Clavijero, al enunciar su teoría de un cruce por un estrecho del norte, no desconocía la versión de Palenque como la ciudad original y de Votán como un sacerdote fundador:

El ilustrísimo Francisco Núñez de la Vega, obispo de Chiapas, dice en el proemio de sus Constituciones sinodales que en la visita de su diócesis que hizo hacia el fin del siglo pasado, encontró muchos calendarios antiguos de los chiapanecos y un viejo manuscrito en la lengua de aquel país hecho por los mismo indios, en el cual se decía, según su antigua tradición, que un cierto Votan [en nota al pie: Votan es el principal entre aquellos veinte hombres ilustres que dieron su nombre a los veinte días del mes chiapaneco] intervino en la construcción de aquel gran edificio que se hizo por orden de su abuelo para subir al cielo; que allí se dio a cada pueblo su lenguaje y que el mismo Votan fue encargado por Dios de hacer la división de las tierras de Anáhuac. Añade después que había en su tiempo en Teopixca, lugar grande de aquella diócesis, una familia de apellido Votan, que se creía descendiente de aquel antiguo poblador. Yo no pretendo hacer creer tan antigua la población de América sobre la fe de aquella tradición de los chiapanecos, sino solamente dar a conocer que los americanos se repuntaban descendientes de Noé (Clavijero, 1964: 427).

Para Clavijero resultaba improbable la llegada de un sacerdote en tiempos de la Torre de Babel, más aún, teniendo como centro fundador las tierras selváticas de Chiapas. No obstante, demuestra que en 1780 la hipótesis de Palenque como ciudad original competía con la mítica Tula y Aztlán de los aztecas, y el Templo de la Cruz era considerado como probable evidencia de un cruce pretérito de Santo Tomás de Aquino. Quizá para salvar esta situación, Clavijero se permitió suponer que el cruce de los animales había sido por "un grande espacio de tierra que unía la parte ahora más oriental de Brasil a la parte más occidental de África y que todo este espacio de tierra se sumergió tal vezpor algunos grandes terremotos" (Clavijero, 1964: 439); pero más que resolver el problema, Clavijero dejó una gran pregunta a la posteridad, ipor qué no podrían haber cruzado por allí los viejos pobladores americanos y el legendario Votán? Así, en este contexto, para inicios del siglo XIX, si algunos eruditos creían haber encontrado las raíces de los naturales en las ruinas del centro del territorio para justificar la joven nación nacida de la Guerra de Independencia, con Palenque sucedió algo similar.

IV

\section{Palenque: la competencia}

Para mediados del siglo XVIII, entre 1730 y 1740, el cura Antonio de Solís, procedente de Tumbalá, fue nombrado sacerdote de Santo Domingo de Palenque. Llegó rodeado de hermanos y tres sobrinos y al buscar tierras de cultivo encontró unas "casas de piedra" que eran los restos de la ciudad maya de Palenque. Uno de los niños con el transcurrir de los años, conservó el recuerdo de aquella arquitectura magnífica y después al irse a estudiar a Ciudad Real, contó la aventura a uno de sus amigos. Este confidente, don Ramón Ordóñez y Agüiar también sobrino-nieto de Solís, tuvo después una excepcional fascinación por las antigüedades, se ordenó sacerdote, organizó una pequeña expedición en 1773 (Navarrete; 2000: 14. Ruz Lhuillier; 1992: 9-30. Alcina; 1995. Díaz Perera; 2009) y escribiría más tarde, siendo "presbitero domiciliario de Ciudad Real de Chiapas y residenteen Guatemala" un libro polémico, "absurdo" — dice Bernalconservado sólo en versión manuscrita titulado Historia 
de la creación del cielo y de la tierra conforme al sistema de la gentilidad americana (Bernal; 1979: 80).

Cincuenta años sobre poco más o menos habrá que (en virtud del título real, colación y canónica institución) se posesionó del Curato de Tumbalá cuyo anexo o pueblo de visita es el Palenque - el Lic. Antonio de Solís, originario de Ciudad Real de Chiapa, y tío abuelo del que escribe estas noticias. Este nuevo beneficiado llevó consigo a un hermano, tres hermanas y tres sobrinos, todos casados; y — quizá aficionado de la benignidad del clima - fijó su residencia en el Palenque, en donde se estableció su expresada familia. [...]...comenzaron a franquear la espesura de aquellas montañas que hasta entonces jamás habían sido holladas por los españoles. [...] No tardaron mucha contingencia en ponerles a la vista algunos de los principales edificios de aquella ciudad [...] desde entonces avaluada corte de un imperio desconocido (Castañeda, 1946: 19).

Éste informó de las ruinas a un hombre ilustrado, don José de Estachería, presidente de la Audiencia, gobernador y capitán general de Guatemala. La existencia de estos personajes que se concentraron en la Sociedad Económica de Amigos del País fundada en Guatemala en 1784 y después en la propia de Chiapas (Cuadro 9 de Carvalho, 1994: 250-251), en el contexto de las guerras europeas en contra de España, alentó - como ha demostrado insistentemente Carlos Navarrete- la formación de grupos ilustrados con incipientes intereses nacionalistas que buscaron indagar en los orígenes de las civilizaciones indígenas con preocupaciones anticuarias quizá más avanzadas que las del centro de México.

...expediciones palencanas no fueron casuales; obedecieron a los afanes de pensadores locales igualmente ilustrados [que los del centro de México], surgidos en un entorno social con matices diferentes, modelados por una educación superior de larga tradición, con contactos culturales propios al exterior, y también en la dolorosa confrontación con el abandono y atraso social de los pueblos. Poseedores de un pensamiento político que pugnaba por los mismos derechos que trataban de lograr los criollos del centro de la Nueva España, cultivaban iguales sentimientos nacionalistas y quizá doblemente, pues tanto impugnaban los privilegios de los peninsulares, como la discriminación hacia los nacidos en las provincias de parte de las autoridades centralizadas en la capital del virreinato (Navarrete, 2000: 11).

A criterio de Navarrete, si bien se realizaron algunas excavaciones pioneras en el centro de México, éstas fueron acontecimientos aislados y sin respaldo gubernamental. Carlos de Sigüenza y Góngora efectuó algunas en la Pirámide del Sol en Teotihuacán, lo siguió el italiano Lorenzo Boturini que tuvo también, igual que Góngora, un fuerte interés en coleccionar documentos (Bernal, 1979: 53-56. Estudio introductorio de Ballesteros Gaiborois en Boturini, 1990: IX-LIV.); el franciscano Agustín de Vetancurt (1620-1700), el jesuita Francisco de Florencia (1620-1695), incluso el famoso viajero Juan Francisco Gemelli Carreri (1645-1700) se preguntaron en mayor o menor medida sobre los residuos prehispánicos del centro de México (Bernal, 1979: 46-57; Ortega y Medina, 1953: 47-49). Pero nunca en la intensidad y contexto como sucedió en Chiapas. Así, en conjunto, después de constatar la existencia de Palenque en 1773, se logró entusiasmar a Estachería para que indagara más profundamente en la existencia de las ruinas. En 1784 mandó expediciones, la primera al mando del teniente de alcalde mayor de Palenque, José Antonio Calderón (Navarrete, 2000: 14; Ruz Lhuillier, 1992: 9-30), la segunda con el arquitecto de Obras Reales de la Capitanía de Guatemala, Antonio Bernasconi y la última con el capitán de artillería Antonio del Río en 1787 (Castañeda, 1946: 46; Díaz Perera, 2009). Entregado el último informe en España, Carlos IV (1748-1819) ordenó la exploración 
de una porción más considerable de la Nueva España. Se comisionó al austriaco Guillermo Dupaix, hombre con ciertos conocimientos sobre historia, arqueología y promotor — como se mencionó anteriormente- de la existencia de la Atlántida como origen del hombre americano (Bernal, 1979: 83; Díaz Perera, 2009).

Los alcances de estas exploraciones fueron importantes. Ramón Ordóñez y Agüiar, coleccionista incansable de documentos, fundador de un círculo de "notables vecinos de culto merecimiento" que se reunían para discutir sobre temas de interés local, escribió su libro Historia de la creación del cieloy de la tierra conforme al sistema de la gentilidad americana que trató del supuesto origen y linaje de la realeza palencana. Ordóñez consultó una multitud de fuentes. Se inspiró primordialmente en la monumental obra Constituciones diocesanas del obispado de Chiapa del franciscano erudito Francisco Núñez de la Vega (16341706). Ahí en el Preámbulo se explicó el origen de los indios en base a la descendencia de Canaán, nieto de Noé "cuarenta y dos generaciones fueron las de Cham, y de ellas afirman gravísimos autores son descendientes los indios, que tomaron la denominación de Indo, que pobló la India oriental y occidental" (Núñez de la Vega; 1988: 274). Esto según un "cuadernillo histórico, escrito en idioma de indio" confiscado - y hoy desaparecido - donde se narraba la historia de la creación. Núñez de la Vega encontró que según las creencias nativas varios hombres habían cruzado de Asia a América: Lambat, Been, Chinax y, enfatizando a un tal Votán (Al respecto Navarrete, 1991) negro "por castigo de Dios" y sexto en la cadena de descendientes de Cam, " $a$ este Votán loveneran mucho todos los indios yen alguna provincia le tienen por el corazón de los pueblos" (Núñez de la Vega, 1988: 275). Fundó una ciudad con Been "dice que dejó escrito su nombre en la piedra parada, que es un sitio que está en el pueblo de Comitlán [Comitán]" (Núñez de la Vega, 1988: 276). Y cerca efectivamente había existido un asentamiento prehispánico importante: Palenque. Pero el objetivo de Núñez de la Vega no era heredar la localización de la ciudad original (como sí lo creyó Ordóñez y Agüiar), sino advertir a los indios como producto de un castigo divino, con costumbres que debían corregirse. La obra Constituciones diocesanas del obispado de Chiapas tenía un fin eminentemente doctrinario: el triunfo ante la llegada futura del Anticristo y favorecer la redención de los justos.

Después de 200 años casi, que ha les amaneció la luz del Evangelio, se hallan los indios en todo lo más de este reino de la Nueva España y Guatemala, tan llenos de sus primitivos errores, supersticiones y maleficios, que apenas hay pueblo donde cada años no sucedan muertes hechas por hechiceros y hay casas y familias conocidas, que como patrimonio y herencia se suceden de padres a hijos en aquestas maldades tan abominables, a quienes los demás indios miran con gran temor, porque con sola la vista y con ciertas palabras con que invocan al Demonio les quitan la vida, o hacen que la pasen rabiando dolores y enfermedades estupendas [...] Exhortamos a todos los sacerdotes y ministros, coadjutores nuestros, que con gran ánimo procuren amoldar los corazones de estos miserables indios a la católica doctrina, apacentándolos continuamente con las verdades de la fe y trayéndoles siempre a la memoria la ruina y daño que han de padecer los que se dejaren llevar de ardides tan diabólicos (Núñez de la Vega, 1988: 290).

Siguiendo así a Núñez de la Vega, Ramón Ordóñez y Agüiar dividió su Historia en dos libros, el primero trató sobre "la creación del mundo, hasta la asención de Jesu Christoá los cielos [además de] la transmigración de los indios, desde Ásia á la América", el segundo "los Annales de los indios, una caval descripción de la Ciudad Palencana" (Ordóñez y Aguiar; s/f: 4). Ahí retomó la idea del viaje de Votán del linaje de las culebras que llegó y fundó Nachán, Palenque, después de haber recorrido España, Roma y Jerusalén. A pesar de una aparente continuidad entre la obra de ambos eclesiásticos, hubo diferencias sustanciales: en Ordóñez imperó un afán inédito por encontrar el sitio prehispánico que tuvo la intención de justificar 
la existencia de una civilización. En este sentido, la llegada de Votán explicó el desarrollo de alta cultura americana en la antigüedad, los nativos por sí mismos eran incapaces de fundar una ciudad como Palenque. De forma similar a Oviedo y Gómara, insistió en que los nativos incluso habían recibido la enseñanza de antiguos apóstoles y, bajo la revelación de augurios a Moctezuma, la conquista estaba anunciada como remedio. De esta suerte, los naturales fueron visualizados como seres incapaces de vivir sin una protección paternalista. No resultaba anormal entonces que don José Ordóñez (hermano del párroco) estuviera inmerso en pleitos judiciales que lo acusaban de explotación excesiva en las haciendas de su hermano Ramón, dado que el indígena era considerado como diferente e inferior al europeo. La versión de Votán y Natchan justificaba el presente colonial pero al mismo tiempo favorecía la identidad y el poder creciente de los criollos chiapanecos y guatemaltecos y sirvió para fundar una expectativa de futuro independiente aunque concebido siempre bajo un poder patronal que menospreciaba totalmente al nativo americano.

Pero volviendo a los hechos, durante la estancia de Ordóñez en Guatemala, frecuentó algunos círculos de discusión donde conoció y prestó su manuscrito al doctor italiano Paul Félix Cabrera. Poco después, éste último escribió un raro documento titulado Teatro crítico americano que, según un pleito judicial en 1794 en la Real Audiencia de Guatemala, resultó ser un plagio (Belaubre, 2007; Díaz Perera, 2009). Esto no detuvo que 28 años después, en 1822, en el contexto de la separación guatemalteca, el apócrifo escrito de Cabrera junto con el Informe de Antonio del Río apareciera en manos del impresor londinense Henry Berthoud que los publicó como Description of the Ruins of an Ancient City, Discovered near Palenque... from the Original Manuscript Report of Captain Don Antonio del Rio: Followed by Teatro Critico Americano by Doctor Paul Felix Cabrera (Brunhouse, 1992: 19; Díaz Perera, 2009). Este libro tendría resonancia intercontinental. Los americanistas a ambos lados del Atlántico lo conocerían y discutirían, sería un referente ineludible para aquellos que se introdujeran en la espesa selva chiapaneca buscando derruidas ciudades mayas. De esta manera, por las injusticias del destino, las ideas de Ordóñez serían indirectamente conocidas generando interesantes concurrencias que resultarían relevantes para el posterior reconocimiento de las ruinas mayas mexicanas y centroamericanas.

\section{$\mathrm{V}$ \\ Un "nacionalismo regional"}

Sin embargo, antes de mencionar los alcances europeos de las exploraciones novohispanas de Palenque, conviene mencionar algunos de los intereses de Ramón Ordóñez a través de la correspondencia que reproduce Carlos Navarrete. Entre 1795 y 1802 se fundó, con el apoyo de la Sociedad Económica de Amigos del País, el Gabinete de Historia Natural en Guatemala. Ordóñez, siempre polémico y "terco" — dice Navarrete—, había mandado en 1799 una propuesta al presidente y capitán general de la Real Audiencia de Guatemala, José Domás y Valle, para que:

se funde es este misma Ciudad Real un gabinete o salón para la gloria destas provincias, en merecimiento a las ventajas de la educación y el progreso donde reunance las figuras antiguas, medallones de piedra y retratos de los reyes Quichés y cuente de sus antepasados de Lacandonia que en tiempo y años reuní, y demás personas de celo como el mío, que de no guardarlas hubiéranse perdido. / No busco fatuas lisonjas y si reuní antiguos papeles fue a gloria del Soberano y de mi patria, en prueba sin equívoco de los antiguos linajes que aquí gobernaran y ennoblecieron en enigmática fecha de grandeza americana (Navarrete; 2000: 34).

Pero no sólo fue un esfuerzo aislado. A sus tertulias asistían individuos con intereses similares. Ordóñez 
era un hacendado respetado, en palabras del historiador Roberto Romero Sandoval, "una persona ampliamente conocida dentro de los círculos intelectuales de Guatemala" (Belaubre, 2007). Nació el 11 de octubre de 1739, ejerció el servicio eclesiástico desde temprana edad y ocupó puestos en todos los niveles de la Iglesia. Hijo de cristianos viejos, su padre fue el sargento mayor Nicolás Ordóñez de Villaquirán y su madre María de Agüiar y Seixas. Nieto de don Pasqual Ordóñez de Villaquirán y de doña Marina de Solís (hermana de Antonio de Solís, descubridor de Palenque), tenía parentela poderosa. Su tía María Ignacia Agüiar y Seijas se casó con el oidor de México Francisco Antonio de Velasco y Rodera. Tuvo dos hermanas (María Teresa y Antonia Rosa) y dos hermanos, el cura José Ordóñez y el médico y rector del Colegio Mayor de Santa María de todos los Santos en la Ciudad de México, Manuel Ordóñez.

El inquieto párroco atendió los curatos de Zinacantan y Totolapa y "en general parece no haber descansado nunca de sus labores religiosas". Con 71 años seguía en servicio solicitando sólo algunas prerrogativas por sus enfermedades y avanzada edad. Debió su formación — según decía- - "los ejemplarísimos religiosos de laSagrada Religión de la Compañía de Jesús, de esta ciudad”. Su dedicación eclesiástica debió haberle permitido acceder a ciertas bibliotecas, archivos, así como al conocimiento del tzeltal, tzotzil y quiché. Invitaba a sus amigos y a su hermano José a visitar las reuniones donde se trataban temas de política, de historia y, por ende, sobre las exploraciones de Palenque:

[...] al igual que yo otras personas tienen el mismo ánimo interesado en cosas, escritos y memorias de todo aquello que nuestra patria guarda, y de cuyos progresos la historiainformaráal mundo, reuní vecinos de culto merecimiento despojados de toda ambición, para que a costumbre de junta intercambiáramos noticias de aquella ciudady de los beneficios de un gobierno justo podrá tomar con su descubrimiento para beneficiar la cultura desta nación. Diligente empeño pusieron en esta empresa D. Vicente Mazariegos y D. Nicolás su hermano y sin mediar fatigas ha venido descuidando la atención de su hacienda cuando lo hemos requerido, y esperamos que puedas venir a nos sin menoscabo de tus ocupaciones (Navarrete, 2000: 83, las cursivas son mías).

Su ímpetu también encontró eco en 1816-1818, cuando promovía la industria de la grana entre los párrocos del Obispado de Chiapa y Soconusco y envió muestras de tela teñida a la Sociedad Económica de Guatemala. Su situación de hacendado le otorgaba también conexión con otros grupos poderosos. Sus tendencias nacionalistas convenían a este círculo que había tomado un poder político y promovió después la independencia de Guatemala. A principios del siglo XIX aparecieron los primeros movimientos armados (Fernández, 1995: 101-144; Wortman, 1991: 79-162 y 233-294; Solórzano, 1992: 13-71). Las intenciones de Ordóñez se vieron reflejadas también en otra carta de enero de 1822 (a poco de haberse declarado la Independencia).

Le decía a María que el tiempo de preocuparse ha pasado y que la patria camine esté en manos de los Ciudadanos, en el Trabajo y en declarar: iLa Justicia es todo! De mi humilde granico solo espero reconocimiento a una labor en que dejé, la vida y la salud y no a poco a costa de mi patrimonio. Escribiré a las nuevas Dignidades acerca de los papeles y cuanto arte y objeto haya reunido de aquí y de allá, caro sería a mi verlos en lugar público destinado a la Educación. Pero es cosa de Dios Ntro. su destino (Navarrete; 2000: 84).

El célebre y dedicado sacerdote murió el 28 de enero de 1825 en Ciudad Real de Chiapa como dueño junto con su hermano José, de las fincas "La Herradura", "El Trapiche de la Merced" y "Labor del Seminario" (Navarrete; 2000). Todavía alcanzó a conocer a Guillermo Dupaix que viajó, casi veinte años después 
de las tentativas de Estachería, por buena parte de México: Veracruz, Morelos, México, Tlaxcala y Oaxaca. Si bien pronto los reportes quedaron archivados en la ciudad de México, las dudas y preguntas sobre el origen siguieron circulando, alentando una clara postura nacionalista regional y, a la posteridad, animando nuevas exploraciones a Palenque.

Talfue el caso de un par de publicaciones misteriosas. Como menciona Catalina Rodríguez Lazcano en su ensayo "La interpretación nacional", el 7 de noviembre de 1827 apareció en El para-rayo de la capital de Chiapa un artículo titulado "Ruinas de Palenc o su historia fantástica". En Yucatán también aparecieron algunos artículos sobre Uxmal (Rodríguez; 1987: 305). Pero en particular ese artículo sobre Palenque fue conocido en dos versiones, una reducida que circuló en forma de volantes en 1817 y otra más extensa. Para estos momentos, Guatemala y Chiapas estaban en un vaivén provocado por las guerras intestinas. Habían surgido insurrecciones en 1811 en Nicaragua, en 1813 en Guatemala y en 1811 y 1814 en El Salvador. Finalmente se declaró la independencia de España el 15 de septiembre de 1821. Ante la inminente llegada de tropas en junio de 1823 después de la abdicación del emperador mexicano, un congreso reunido en Guatemala se pronunció a favor de la separación total. En 1824 se promulgó la Constitución Federal de Centroamérica mantenida hasta 1838-1839 cuando finalmente se dispersaron los territorios y formaron varios países independientes. No obstante, Chiapas, a pesar de su contacto y permanencia con la Audiencia de Guatemala, después de 1823, se mantuvo todavía un tiempo autónoma y formó su propio gobierno hasta el plebiscito del 14 de septiembre de 1824 cuando se decidió la anexión a México por el Congreso Directivo de Chiapas (Pérez, 1997: 79-106; Zebadúa, 1999: 81-96). En este contexto aparecieron las dos versiones de "Ruinas de Palenc o su historia fantástica".

La crónica versa sobre el encuentro del autor con un fantasma palencano en el "Palacio de las Lajas" (hoy conocido como el Templo de las Inscripciones), donde le narra el declive de la gran república de Lacandonia o Botannia. Lo invita a aprender de esa experiencia pues "acia el norte, forman un govierno semejante al que destruyó la imprevisión”. El espectro contó cómo se constituyó una asociación de ilustres que se reunían en la oscuridad de la noche, planeaban acciones con tal de apoderarse del poder y se exigían la más ciega obediencia y respeto a los ilustres de primera clase: una forma de poder alterna al Estado que logró consolidarse como una oligarquía, pervertir las instituciones, subyugar a los profanos y establecerse permanentemente. Pronto se aumentaron las contribuciones y paulatinamente se provocó la emigración así como el declive de la industria y el comercio. Cuando el pueblo cayó en conciencia de la infamia ya era demasiado tarde.

¿Cuanta maldad! Hasta mugeres con quienes casarse faltaba á los profanos por la absurda éilegal poligamia que se permitieron los ilustres. Aquella propención natural de amor al país en que nacemos: esta propención que manejada por un gobierno sabio es productiva de mui grandes virtudes: esta propención, repito, se fue apagando por grados hasta apagarse totalmente. Ya mis descendientes no venían á esparcir flores sobre mi sepulcro, ni daban cuenta a mi sombra que eran felices á favor de las instituciones (Navarrete; 2000: 42). ${ }^{5}$

Los pobladores de Lacandonia o Botannia, que antaño amaban a su gobierno, huyeron a las selvas y prefirieron vivir entre las fieras antes que aceptar un poder perverso. Ahí terminó el relato del fantasma. Carlos Navarrete hace notar cómo algunas palabras se modificaron en ambos escritos (despotismo/oligarquía, monarquía/ república, reino/mando, respectivamente). Hay que recordar que la primera versión apareció en 1817 cuando el poder colonial todavía se mantenía en América y la segunda en 1827 después de la anexión chiapaneca a México y la independencia Guatemalteca. Es decir, ambos textos sirvieron para voluntades políticas 
distintas, pero con una connotación separatista y/o independentista.

Hasta el punto que Palenque sirvió como escenario para delinear una moraleja histórica y prevenir el desastre del país y/o república naciente. Un espejo del fervor nacionalista y separatista entre los ilustrados chiapanecos y guatemaltecos, que cristalizó en la independencia de los segundos y una dura crítica sobre el futuro político mexicano así como el intento malogrado de separar Chiapas. El autor muy probablemente conoció la obra de Ramón Ordóñez (quizá asistía a sus tertulias) y conectó claramente la majestuosidad del pasado indígena con el presente político y las esperanzas de una provincia independiente. El autor posible fue don fray Matías de Córdova (1768-1828), lector de los enciclopedistas, ganador en 1797 del Concurso de Mérito convocado por la Sociedad Económica de Amigos del País y fundador del periódico donde se publicó la crónica (Navarrete, 2000).

En medio de estos aconteceres políticos y de la inercia de las exploraciones a la selva chiapaneca no habría que ignorar cómo, de igual manera, empezaron a crecer también dudas sobre la esencia de los vestigios yucatecos y guatemaltecos que provocaron artículos en revistas y libros regionales. Ante la duda sobre la probable unidad histórica de la región (que después se llamaría maya), Palenque gozaba de una característica notable: se entendía como las ruinas de la ciudad original (Díaz Perera, 2009). Un discurso histórico que se tradujo en prácticas políticas concretas, ya fueran separatistas en el caso de los ilustrados mexicanos o, a partir del siglo XIX, colonialista, según los viajeros anticuarios ulteriores.

\section{VI}

\section{Una trayectoria inesperada}

En la Société de Géographie de París el ll de noviembre de 1825, en sesión de la Comisión Central, el anticuario
David Baillie Warden leyó unos fragmentos de Description of the Ruins of an Ancient City, Discovered Near Palenque, in the Kingdom of Guatemala in Spanish America, cuyo relato intrigó a los miembros ("Commission Centrale", 1825: 310-311). Para mayor curiosidad, el viajero y sabio prusiano Alexander von Humboldt (1769-1859), en su bella obra con fecha de 1810, Vues des cordillères et monuments des peuples indigènes de l'Amérique, editada bajo la imprenta de J. H. Stone, había escrito:

Con anterioridad llamamos la atención a nuestros lectores sobre este Votan o Wodan americano, que parece de la misma familia de los Odines o Wodos de los godos y los pueblos de origen celta. Como de acuerdo con las sabias investigaciones de sir William Jones, Odín y Buda son probablemente una misma persona. [...] Según las antiguas tradiciones recogidas por el obispo Francisco Nuñez de la Vega 'el Wodan de los chiapanecos era nieto de ese ilustre anciano que, por la época de la gran inundación en la que pereció la mayor parte del género humano, fue salvado en una balsa en compañía de toda su familia. 'Wodan cooperó en la construcción del gran edificio que los hombres intentaron hacer para llegar a los cielos, pero la ejecución de este temerario proyecto fue interrumpida y cada familia habló, desde entonces, una lengua diferente; aún más: el gran espíritu Teotl ordenó a Wodan que fuera a poblar el país de Anahuac (Labastida, 1999: 304).

Humboldt creía factible la existencia de Votán aunque se negó a refrendar su existencia. Extrañados, intrigados, los integrantes de la Société de Géographie de París emitieron una convocatoria con un premio de una medalla de oro y 2,400 francos solicitando a los viajeros demostrar la existencia de Palenque ("Cinqueme Prix", 1826: 595-596; Díaz Perera, 2009). Entre los interesados, partieron con rumbo a la oscuridad de la selva, el médico francés François Corroy y el militar Juan Galindo (Díaz Perera, 2009; Díaz Perera, 2008: 5-110; López 
Luján, 2006: 22; Bernal, 1979: 91); pero sorpresivamente también apareció el excéntrico coleccionista alemán Johann Frédéric Maximulianus Waldeck (1768-1875) (Díaz Perera, 2008, Díaz Perera, 2009; Brunhouse, 1992; Baudez, 1993; Echánove, 1986), que daría continuidad a esta versión del sacerdote fundador convirtiéndose en continuador indirecto de los postulados de Francisco Núñez de la Vega y Ramón Ordóñez y Agüiar.

El alemán y longevo coleccionista llegó en marzo de 1832 a Santo Domingo de Palenque. No desconocía las antigüedades del sitio.Como pintor por encargo había realizado en 1822 parte de las imágenes de Description of the Ruins of an Ancient City, Discovered near Palenque... from the Original Manuscript Report of Captain Don Antonio del Rio: Followed by Teatro Critico Americano by Doctor Paul Felix Cabrera. Sin embargo, quedó perplejo al conocer directamente los edificios. En el Templo de la Cruz vislumbró varias figuras ricamente ataviadas y supuso distinguir una indudable influencia asiática.En el Journal de Potche o diario de bolsillo de 1832, siguiendo las entrevistas a un supuesto nativo misántropo, Pedro López, Waldeck escribió sobre Votán lo siguiente:

Las tradiciones que me han sido comunicadas con el misántropo de las ruinas me parecen valer la pena de ser recogidas. Ya que este hombre de una gran instrucción, lleva en su fisonomía el sello de la sinceridad y no tiene ningún motivo de engañarme. Todo lo que contiene este pequeño diario es el resumen de lo que me dijo. No hay orden en el curso de los hechos puesto son el resultado de respuestas que hacía a mis preguntas. El verdadero nombre de las ruinas de Palenque es Natchan, y no Otitoiun que es una palabra extranjera a la lengua chole [chol], y que sería más bien maya, idioma que deriva de él. Alrededor de diez siglos antes del nacimiento de Cristo, vino del lugar donde se levanta el sol, tres individuos blancos y barbudos, el primer sabio Ymas, el segundo Ik, el tercero Votán, aquel que obtuvo toda la celebridad que la tradición [entonces] le otorgó. A pesar de que el maíz sea indígena no estaba como en su tiempo en el paisaje y es Votán que les trajo esta maravilla, él lo unió a la civilización y las artes. La época de su muerte es un problema, la tradición si es justa, lo hizo morir de manera violenta y nueve reyes lo sucedieron e iban a reinar cada uno medio siglo según el uso que él mismo había prescrito. Si un soberano moría antes de terminar su tiempo, el reino continuaba en su nombre por los ancianos, los hombres más sabios del país, si llegaba al término de su reino y sus facultades intelectuales y corporales se lo permitían, seguía hasta el momento que su debilidad lo volvía incapaz. Es quizá de esta costumbre que Votán debió ser víctima de la ley que había emitido. Un ambicioso le sucedió y su nombre era Chanan (5), los que vinieron después fueron Abaghu (6), Bem (7), Hix (8), Tzequin, Chabin, Chinax, Cahagh y Akbal. Es bajo este último rey que Natchan fue destruida por la nación de Tula ciudad que había sido fundada por Votán y que después [ilegible] enemigo de Natchan [se refería a Toniná], sus ruinas están cerca de Ocosingo (Waldeck, pp. $52) \cdot$

Resulta interesante notar que Waldeck, a pesar de no conocer directamente la obra de Francisco Núñez de la Vega, mencione por el testimonio de un supuesto indio misántropo a Been, Chinax y sólo omitiera a Lambat (io era Cahagh?) como parte de la dinastía de Votán, lo que indica la genuina existencia de estas creencias entre los nativos. Así, al mismo tiempo que la tradición mantenía en el entorno local la tesis del sacerdote fundador, en los círculos intelectuales y de viajeros igualmente supervivía la teoría de una migración fundacional, ligada a una antigüedad simultánea a los pueblos del Viejo Continente. Sin saberlo, la vieja discusión de una migración por el sur, y marítima, alcanzó a atravesar las conclusiones de los primeros exploradores de las ciudades prehispánicas como Alexander von Humboldt y Frédéric Waldeck. Las tesis de Anglería, Durán y Lumnius concebidas entre los siglos XVI y XVIII 
mantenían vigencia en el siglo XIX. Waldeck, sobre Votán insistió:

Al hablar de Votán y de los sabios legisladores a sus discípulos, el ex-cura [Pedro López] me dice que Votán tenía otros nombres que le habían sido dados por las tres naciones a las cuáles había sido consignada la agricultura, las artes e instrucción en las leyes: Cuculcán, Gucumata y Quetzalcóatl, este último nombre dado por los pueblos náhuatl, los últimos que él civilizó y lo sacaron de su territorio./ Esta tradición me llena de alegría por amor, porque tenía desde hace mucho tiempo la sospecha de que estos legisladores habían venido de Palenque y que salidos de ahí habían regresado a Natchan. Encontré, sin embargo, una diferencia de tiempo que molesta la tradición y la vuelve sospechosa. Es que Natchan fue destruida sólo algunos años después de Votán y que es hacia el comienzo del reino de Akbal que los toltecas aparecieron en Anáhuac, ihabría entonces varios Votán como hubo varios Hércules? Chibalba y Natchan fueron destruidas por los Olmecas y los Xicalancas que tenían su capital cerca de Ocosingo y esto prueba que eran más antiguos que los toltecas que se decían más tiempo establecidos en el país. Finalmente no puedo reconciliar estos puntos de la tradición, sólo separando Quetzalcóatl de Votán que fue el jefe de la dinastía Natchana mientras que Quetzalcóatl sería el de la dinastía Olmeca y Xicalanca y sería él o sus descendientes que habrían destruido el imperio de Votán (Waldeck, pp. 58-59).

El alemán creyó que Palenque era una antigüedad mucho mayor que la de los toltecas "que se decían más tiempo establecidos en el país" y donde había recalado Votán después de una migración marítima por el oriente, similar a como había dicho Ordóñez y Agüiar con tal de fundamentar la identidad de un territorio independiente en los confines de la Nueva España. Pero Waldeck insistió no por un interés nacionalista, sino porque así lo insinuaba la convocatoria de la Société de Géographie, "el autor acopiará todo lo que se sabe sobre el Votan o Wodan de Chiapanais, personaje comparado a Odin y a Boudda./ Este premio se otorgará en la primera Asamblea general de 1832" "“Cinqueme Prix", 1826: 595). Precisamente, la teoría de Palenque como ciudad original competía con fuerza con la versión del centro-norte de la Nueva España e inclusive se discutía en círculos eruditos de relevancia como la Société de Géographie de París. El debate sobre los orígenes fundacionales como disputa entre grupos de poder regional novohispanos atravesó el Atlántico y generó expectación entre los eruditos europeos.

De esta suerte, se creyó la existencia del legendario sacerdote refrendando una probable migración marítima. Algunos sabios mexicanos, ya bien entrado el siglo XIX, también lo consideraron.El más distinguido fue el político mexicano y entonces ex-ministro de Relaciones Exteriores e Interiores, el guanajuatense Lucas Alamán (1792-1853), que en su Historia de México mencionó:

Antes de la conquista de los españoles hicieron a principios del siglo XVI, y á que fueron dando mayor extensión en los dos siguientes, el país se hallaba poblado por diversas naciones, que según sus historias, habían emigrado en distintas épocas de las regiones septentrionales, estando trazado con mucha precisión en sus pinturas geroglíficas el camino que algunas de ellas siguieron desde el norte de California hasta las lagunas mexicanas, y todo inclina a creer que estas emigraciones procedieron de las gran llanura central del Asia, que por un lado lanzó sobre la Europa los enjambres de bárbaros que contribuyeron á destruir el Imperio Romano, y por el otro las tribus que poblaron el continente Americano: sin negar por esto que hubiese otra emigración por el Atlántico, más antigua y de pueblos más adelantados en cultura, de los que ya no quedaba ni memoria en el siglo de la Conquista, y solo son conocidos por las gigantescas ruinas 
de Palenque y las que se ven todavía en varios puntos de Yucatán (Alamán, Historia, t. I; 1972: 12. Las cursivas son mías).

Al final, la competencia de ambas versiones se inclinó a favor de aquella que daba por válida al centro-norte con la consolidación del epicentro de la naciente nación mexicana en el altiplano, creando por ende mitos, símbolos y un origen nacional basado en el águila parado sobre un nopal devorando una serpiente y justificando la noción de los aztecas y toltecas como génesis de lo mexicano. En cambio, la desventurada escisión de Guatemala y Chiapas acabó con los intentos de considerar los fundamentos de una nación distinta en los confines de la Nueva España y Ramón Ordóñez y Agüiar, Francisco Nuñez de la Vega, José de Estachería y el mismo Frédéric Waldeck se hundieron en el olvido, al grado que la Historia de la creación del cielo y de la tierra conforme al sistema de la gentilidad americana, máxima obra del párroco chiapaneco, nunca alcanzó imprenta y quedó en versión manuscrita. Con todo, la región mantuvo todavía presencia indígena cimarrona y la tesis de Votán se sostuvo. La versión del sur como sede de la civilización americana guardó silencio para aparecer, como si nunca hubiera existido, a finales del siglo XX con un evento que puso precisamente en entredicho la noción epicéntrica de lo mexicano y cuestionó los mitos y símbolos del estado-nacional. Votán, sorprendentemente, seguía vivo y se mostró de la forma más inesperada.

VII

\section{¿La discusión prosigue? A manera de cierre}

El primero de enero de 1994, el mismo día que entró en vigor el Tratado de Libre Comercio de América del Norte (TLCAN), un grupo autodenominado Ejército Zapatista de Liberación Nacional (EZLN) integrado en su mayoría por naturales tomó por las armas varias cabeceras municipales de los Altos de Chiapas. Después de una contraofensiva del ejército federal, el repliegue de las tropas y el inicio de las negociaciones de paz, el 10 de abril, un día antes del aniversario del asesinato de Emiliano Zapata, el EZLN emitió un raro comunicado:

Desde la hora primera de esta larga noche en que morimos, dicen nuestros más lejanos abuelos, hubo quien recogió nuestro dolor y nuestro olvido. Hubo un hombre que, caminando su palabra desde lejos, a nuestra montaña llegó y habló con la lengua de los hombres y mujeres verdaderos. Era y no era de estas tierras su paso, en la boca de los muertos nuestros, en la voz de los sabedores ancianos, caminó su palabra de él hasta el corazón nuestro. Hubo y hay, hermanos, quien siendo y no siendo semilla de estos suelos a la montaña llegó, muriendo, para vivir de nuevo, hermanos, vivió muriendo el corazón de este paso propio y ajeno cuando casa hizo en la montaña de nocturno techo. Fue yes su nombreen las nombradas cosas. Se detiene y camina en nuestro dolor su palabra tierna. Es y no es en estas tierras: Votân Zapata, guardián y corazón del pueblo (Monsiváis, t. I; 2003: 210-213.)

Contundente, el EZLN insistió "Votán, guardiány corazón del pueblo. Y nuestro camino innominable y sin rostro, nombre tomó en nosotros: Ejército Zapatista de Liberación Nacional" (Ibídem). Entre las reivindicaciones de tierra, los insurgentes se definieron como una continuidad resucitada de aquél sacerdote que a finales del siglo XVIII y principios del XIX se presumió como existente por un grupo de criollos nacionalistas. Al igual que Ordóñez Aguiar, Francisco Nuñez de la Vega y José de Estachería, el EZLN recurrió al pasado prehispánico y a creencias milenarias con propósitos identitarios y políticos. Y no habría que extrañarse. Después de Humboldt y Waldeck hubo otros personajes que insistieron en la existencia de Votán; uno de los más 
célebres fue el francés, descubridor del Popol Vuh, Charles Étienne Brasseur de Bourbourg (1814-1874), en Histoire des nations civilisées du Mexique et de l'Amérique Centrale, publicado en 1857 (Larrainzar, 1876: 333337). Pero más notable fue que, en pleno siglo XX, el erudito chiapaneco Enrique Santibañez, miembro del Liceo Altamirano y de la Sociedad Mexicana de Geografía y Estadística, presentara en el XVII Congreso Internacional de Americanistas un trabajo titulado Votán y el origen de la civilización americana que vería la luz en forma de folleto en 1910 (Santibañez, 1910). También en forma de novela, en la ciudad de Puebla, un tal Mauricio de Bracy publicó Nachan: novela de las ruinas hizo referencia al enigmático sacerdote (De Bracy; 1924). ${ }^{7}$ Pero lo más notable fue que se mantuvieran tales creencias en los propios nativos chiapanecos que, como insistían hasta hace algunos años los guías de turistas (experiencia que escuchó en su infancia el autor de estas líneas), remitían la Tableta Oval del Palacio a una representación de Votán. Notable que después de 350 años esta leyenda se mantuviera viva, reivindicando y exigiendo el reconocimiento de los principios indígenas y se pusiera en entredicho la noción epicéntrica de la nación mexicana al reclamar el reconocimiento de las comunidades olvidadas en las oscuridades de la selva chiapaneca.

Independientemente del uso que hiciera el EZLN, el uso del simbolismo de Votán demuestra que todavía la historia no es (ni será nunca) un conocimiento aséptico, puro y cristalino, sino el centro de disputas y prenociones con impacto en acciones políticas, en este caso, la generación de una identidad rebelde frente al Estado mexicano. Si bien los afanes independentistas y/o separatistas están superados, con el olvido y segregación milenaria de los nativos chiapanecos, el pasado ligado a un nacionalismo criollo que buscó el sueño de una nación en el sureste novohispano ha renacido para ser - parafraseando a Navarrete - todavía un "tema no resuelto" (Navarrete, 1991).

\section{Notas}

${ }^{1}$ Ver Joseph de Acosta, "Los primeros pobladores de las Indias"; Juan de Torquemada, "Monarquía Indiana"; Bernardino de Sahagún, "Historia general de las cosas de la Nueva España” en Matos; 1987: 33-49, 51-84 y 29-31.

${ }^{2}$ Esta teoría también fue refrendada por Agustín de Zárate (1514?-1560) en 1555 en Historia del descubrimiento y conquista de la provincia del Perú y Francisco Cervantes de Salazar (1514?-1575) en su Crónica de la Nueva España. Los promotores de este continente perdido se basaron en los apuntes de la tragedia de Séneca, Medea, y de Platón en sus diálogos el Critias y el Timeo.

3 El dominico Gregorio García (1554-1627), autor en 1607 de Origen de los indios del Nuevo Mundo e Indias Occidentales, no lo descartaba del todo en su Predicación del Santo Evangelio en el Nuevo Mundo viviendo los Apóstoles; esta versión fue sostenida también en Perú por Alonso Ramos Gavilán (1570-1639) en Historia del Santuario de Nuestra Señora de Copacabana, aparecido en 1621, y Felipe Guamán Poma de Ayala (1538?-1620?) en Nueva crónica y buen gobierno de 1627.

${ }^{4}$ Los afortunados fueron el teniente Esteban Gutiérrez; el alcalde mayor de Ciudad Real, Fernando Gómez de Andrade; el provincial dominico fray Luís de la Roca; Nicolás Velasco, retirado de caballería; y el hermano del párroco, José Ordóñez.

${ }^{5}$ La parte del texto reproducida por el autor está en las pp. 39-43.

${ }^{6}$ Frédéric Waldeck, Journal de Potche de Natchan: nottes de théogonie azteque et variété d'autres, pour servir en voyage Palenque. núm. 24 (Treis) (manuscrito), Newberry Library of Chicago, Colección Ayer, Chicago (Estados Unidos), MS, 1264. La numeración en los bordes superiores de las páginas no corresponden a una serie. Por tanto, se decidió numerarlas nuevamente según un orden sucesivo.

7 Como dato curioso, el volumen está sellado con tinta en las partes donde está la autoría como "J. P. 
Almendaro", lo que permite especular que Mauricio de Bracy es un seudónimo inspirado en el personaje de la novela Ivanhoe de Walter Scott y el verdadero autor, probablemente, sea J. P. Almendaro.

\section{Bibliografía}

Aguilar Camín, Héctor (1994), "La invención de México: notas sobre nacionalismo e identidad nacional", en Estudios Públicos, núm. 55, Santiago de Chile (Chile), Centro de Estudios Públicos, p. 8 y en http://www. cepchile.cl/dms/lang_1/doc_1844.html. [consultado: 19 de marzo de 2007].

Alamán, Lucas (1972), Historia de México, Tomo I, México: editorial Jus, colección "México heroico", núm. 78.

Alcina Franch, José (1995), Arqueólogos o anticuarios: historia antigua de la arqueología en la América española, Barcelona, ediciones del Serbal, colección "Libros del Buen Andar", núm. 39.

Baudez, Claude-Fraçois (1993), Jean-Frédéric Waldeck peintre: le premier explorateur des ruines mayas, París (Francia), Hazan.

Belaubre, Christophe, (2007), Ordóñez y Agüiar, Ramón de, Diccionario biográfico centroamericano, Asociación para el Fomento de los Estudios Históricos en Centroamérica, en http://afehchistoria-centroamericana.org/index.php?action=fi aff\&rid=1461. [consultado: 04 de octubre de 2007.

Ben Israel, Menasseh (1987), Esperanza de Israel, Madrid (España), Hiperión.

Bernal, Ignacio (1979), Historia de la Arqueología en México, México, Porrúa.

Boturini Benaduci, Lorenzo (1990), Historia General de la América Septentrional, México: Universidad Nacional Autónoma de México, Instituto de Investigaciones Históricas, Serie historiadores y cronistas de Indias, núm. 8.

Brunhouse, Robert L. (1992), En busca de los mayas: los primeros arqueólogos, Jorge Ferreiro (trad.), México, Fondo de Cultura Económica.
Cañizares Esguerra, Jorge (2007), Cómo escribir la historia del Nuevo Mundo: historias, epistemologías e identidades en el mundo del Atlántico del siglo XVIII, Susana Moreno Parada (trad.), México, Fondo de Cultura Económica, Sección de obras de historia.

Carvalho, Alma Margarita (1994), La Ilustración del Despotismo en Chiapas, 1774-1821, México, Consejo Nacional para la Cultura y las Artes. (Regiones).

Castañeda Paganini, Ricardo (1946), Las ruinas de Palenque: su descubrimiento y primeras exploraciones en el siglo XVIII, Guatemala.

"Causa formada al Dr. Fray Servando Teresa de Mier, por el sermón que predicó en la Colegiata de Guadalupe el 12 de Diciembre de 1794" (1985), en Hernández y Dávalos, J. E., Historia de la Guerra de Independencia de México, tomo III, México, Instituto Nacional de Estudios Históricos de la Revolución Mexicana, Comisión para las celebraciones del 175 aniversario de la Independencia nacional y 75 aniversario de la Revolución mexicana, (Biblioteca de obras fundamentales de la independencia y la revolución).

Cervantes De Salazar, Francisco (1971), Crónica de la Nueva España, Madrid (España), ediciones Atlas.

"Cinqueme Prix: Antiquités Américaines" (1826), Bulletin de la Société de Géographie, París, Société de Géographie de París, enero-junio.

"Commission Centrale: séance du 11 novembre 1825" (1825), Bulletin de la Société de Géographie, París: Société de Géographie de París, Julio-diciembre.

Cogley, Richard W. (2005), "The Ancestry of the American Indians: Thomas Thorowgood's Iewes in America (1650) and Jews in America (1660)", in English Literary Renaissance, vol. 35, Spring, núm. 2.

Clavijero, Francisco Javier (1964), Historia antigua de México, México, editorial Porrúa, S.A. (Sepan cuántos, núm. 29).

De Bracy, Mauricio (1924), Nachan: novela de las ruinas, Puebla, México, Imprenta "La enseñanza objetiva”.

Del Río, Antonio (1822), Description of the Ruins of an Ancient City, Discovered near Palenque... from the Original Manuscript 
Report of Captain Don Antonio del Rio: Followed by Teatro Critico Americano by Doctor Paul Felix Cabrera, London, Henry Berthoud Publisher, con imágenes de Frédéric Waldeck. Fondo reservado de la Biblioteca del Museo Nacional de Antropología en la Ciudad de México, clasificación F, 219 (al interior está inscrito número 1807, estante VII, tablero 2-29).

Díaz Perera, Miguel Ángel (2008), Deviajeros y coleccionistas de antigüedades. Frédéric Waldeck en México: Historia, origen y naturaleza del hombre americano en los albores de la modernidad, Tesis de doctorado, Michoacán, México, Centro de Estudios Históricos de El Colegio de Michoacán, A.C.

Díaz Perera, Miguel Ángel (2009), "Tras las huellas de Palenque: las primeras exploraciones", en LiminaR. Estudiossocialesy humanísticos, Año 7, vol. VII, núm. 1, junio de 2009, Tuxtla Gutiérrez, México, Centro de Estudios Superiores de México y Centroamérica, Universidad de Ciencias y Artes de Chiapas, pp. 104-134.

Díaz Perera, Miguel Ángel (2009), "El reino de los incapaces. Antigüedad de indio americano en el testimonio de Frédéric Waldeck y François Corroy”, en Seis miradas al Tabasco de siglo XIX, México, Universidad Juárez Autónoma de Tabasco.

Durán, fray Diego (1995), Historiadelas Indias de Nueva España e islas de Tierra Firme, Consejo Nacional para la Cultura y las Artes, México, (Cien textos fundamentales para el mejor conocimiento de México).

Echánove Trujillo, Carlos (1968), Dos héroes de la arqueología maya: Frédéric Waldeck y Teobert Maler, México, Gobierno del Estado de Yucatán, Consejo editorial de Yucatán A.C., (Voces contemporáneas).

Eldridge Huddleston, Lee (1967), Origins of the American Indians: European Concepts, 1492-1729, Austin (EU): University of Texas Press, Latin American Monographs, núm. 11.

Fernández De Oviedo, Gonzalo (1959), Historia general y natural de las Indias, Madrid (España): ediciones Atlas, Biblioteca de autores españoles desde la formación del lenguaje hasta nuestros días.
Florescano, Enrique (comp.) (1993), El patrimonio cultural de México, México, Consejo Nacional para la Cultura y las Artes, Fondo de Cultura Económica.

Jay Gould, Stephen (1987), Time's Arrow, Time's Cycle: Myth and Metaphor in the Discovery of Geological Time, Cambridge, Massachusetts, Harvard University Press.

Labastida, Jaime (1999), Humboldt, ciudadano universal, México, Siglo XXI editores, Secretaría de Educación Pública, El Colegio Nacional, Fondo de Cultura Económica, Colección Tezontle.

Larrainzar, Manuel (1876), Estudios sobre la Historia de América, sus ruinas y sus antigüedades, Tomo IV, México, Imprenta de M. Villanueva Francesconi e hijos.

Lippincott, Kristen, et. al, (1999), El tiempo a través del tiempo, Barcelona: Grijalbo Mondadori S.A., Libro publicado para acompañar la exposición celebrada en The Queen's House, National Maritime Museum, Greenwich, Londres, 1 de diciembre de 1999 al 24 de septiembre de 2000.

López De Cogolludo, Fr. Diego (1957), Historia de Yucatán, J. Ignacio Rubio Mañé (prol.), México, Editorial Academia Literaria.

López De Gómara, Francisco (1979), Historia general de las Indias y vida de Hernán Cortés, Caracas (Venezuela), Fundación Biblioteca Ayacucho, Biblioteca Ayacucho, núm. 64.

López Luján,Leonardo (2006), “La arqueología mesoamericana en la obra de Nebel", en Artes de México (Carl Nebel: pintor viajero del siglo XIX), México, núm. 80.

Mártir De Anglería, Pedro (1964), Décadas del Nuevo Mundo, México: José Porrúa e hijos, Biblioteca José Porrúa Estrada de historia mexicana, núm. 6.

Matos Moctezuma, Eduardo (comp.) (1987), Ideas acerca del origen del hombre Americano (1570-1916), México: Secretaría de Educación Pública/Orígenes del hombre americano, Seminario del 22 al 26 de junio de Museo Nacional de Antropología e Historia, México, D. F., 1987, Cien textos fundamentales para el mejor conocimiento de México. 
Morales Moreno, Luis Gerardo (1994), Orígenes de la Museología Mexicana: fuentes para el estudio histórico del Museo Nacional, 1780-1940, México, Universidad Iberoamericana.

Monsiváis, Carlos, Poniatowska, Elena y García De León, Antonio (ed.) (2003), EZLN: documentos y comunicados (1 de enero al 8 de agosto de 1994), Tomo I, México: Ediciones Era.

Navarrete, Carlos (1991), "Anotaciones a temas no resueltos: Votán, las 'Columnas de Been' y las rocas-estelas en el sur de Mesoamérica”, en Anales de la Academia de Geografía e Historia de Guatemala, Guatemala, Academia de Geografía e Historia de Guatemala, LXV, pp. 5-55.

Navarrete, Carlos (2000), Palenque, 1784: el inicio de la aventura arqueológica maya, México, Universidad Nacional Autónoma de México, Instituto de Investigaciones Filológicas, Instituto de Investigaciones Antropológicas, Centro de Estudios Mayas, Cuaderno 26.

Núñez De La Vega, Francisco (1988), Constituciones diocesanas del obispado de Chiapas hechas y ordenadas por su señoría ilustrísima, maestro don fray Francisco Núñez de la Vega, México: Universidad Nacional Autónoma de México, Instituto de Investigaciones Filológicas, Centro de Estudios Mayas, Fuentes para el estudio de la cultura maya, núm. 6.

Ordóñez y Aguiar, Ramón (s/f.), Historia de la creación del cielo y de la tierra conforme al sistema de la gentilidad americana. Theología de las culebras, figurada en ingeniosos gerogliphicos, symbolos, emblemas y metaphoras, diluvio universal, dispersión de las gentes, verdadero origen de los indios: su salida de Chaldea, su transmigración à estas partes septentrionales; su tránsito por el océano, y derrota que siguieron, hasta llegar al seno mexicano. Principio de su imperio, fundación y destrucción de su antigua y primera corte, poco há descubierta, y conocida con el nombre de Palenque. Supersticioso culto, con que los antiguos palencanos adoraron al verdadero Dios, figurado, en aquellos symbolos ó emblemas, que colocados en las aras de sus templos, últimamente, degeneraron en abominables ídolos. Libros, todos, de la más venerable antigüedad; sacados del olvido unos; nuevamente descubiertos otros; é interpretados sus symbolos, emblemas, y metaphoras; conforme al genuino sentido del phrasismo americano, manuscrito, Archivo de la Biblioteca del Museo Nacional de Antropología de México, en la Colección Antigua, núm. 231.

Ordóñez y Aguiar, Ramón (s/f.), Historia de la creación del cielo y de la tierra conforme al sistema de la gentilidad americana, etc. (obra trunca), México: Museo Nacional,

Ortega y Medina, Juan A. (1953), México en la conciencia anglosajona, México: Porrúa y Obregón S.A., México y lo mexicano, núm. 13.

Pease, G.Y. Franklin (1999), "Temas clásicos en las crónicas peruanas de los siglos XVI y XVII", en Hampe Martínez, Teodoro (comp.), La Tradición clásica en el Perú virreynal, Lima (Perú): Fondo Editorial Universidad Nacional Mayor de San Marcos, versión digital de la Biblioteca Central de UNMSM, en http:// sisbib.unmsm.edu.pe/bibvirtual/libros/historia/trad clas/Temas_clasic_cron_per.htm. [consultado: 17 de marzo de 2007).

Pérez Brignoli, Héctor (recop.) (1997), Breve historia de Centroamérica, México: Alianza, Alianza América, Historia de América Latina, núm. 7.

Ruz Lhuillier, Alberto (1992), El Templo de las Inscripciones: Palenque, México: Fondo de Cultura Económica, Sección de Obras de Antropología.

Santibañez, Enrique (1910), Votány el origen de la civilización americana, México: tipografía "Artística".

Suárez De Peralta, Juan (1949), Tratado del descubrimiento de la Indias y su conquista y de los ritos y sacrificios y costumbres delos Indios; y de los virreyes y gobernadores, especialmenteen la Nueva España, y del suceso del marqués del Valle, segundo, don Martín Cortés; de la rebelión que se le imputó, y de las justicias y muertes que hicieron en México los jueces comisarios que para ello fueron por Su Majestad: $y$ del rompimiento de los ingleses, y del principio que tuvo Francisco Drake para ser declarado enemigo, México: Secretaría de Educación Pública, Testimonios mexicanos: historiadores, núm. 3. 
Toulmin, Stephen y Goodfield, June (1990), El descubrimiento del tiempo, Néstor Miguez (trad.), Barcelona (España): Paidós, Paidós Studio/ Básica.

Veytia, Mariano (1979), Historia antigua de México, tomo I, México: Editorial del Valle de México S.A.

Waldeck, Frédéric (1832), Journal de Potche de Natchan: nottes de théogonie azteque et variété d'autres, pour servir en voyage Palenque, núm. 24 (Treis), Chicago (Estados
Unidos): Newberry Library of Chicago, Colección Ayer, Archivo: MS, 1264.

Wortman, Miles L. (1991), Gobierno y sociedad en Centroamérica. 1680-1840, San José: EDUCA.

Zebadúa, Emilio (1999), Breve historia de Chiapas, México, El Colegio de México: Fondo de Cultura Económica, Fideicomiso Historia de las Américas, Serie Breves Historias de los Estados de la República Mexicana. 